\title{
Personally tailored teaching in WHURLE using conditional transclusion
}

\author{
Adam Moore \\ Timothy J. Brailsford \\ Craig D. Stewart \\ University of Nottingham, UK \\ University of Nottingham, UK \\ University of Nottingham, UK \\ Telephone: +441158466492 \\ Telephone: +441159514231 \\ Telephone: +441159513238 \\ E-mail:adam.moore@nottingham.ac.uk E-mail: tim.brailsford@nottingham.ac.uk E-mail:craig.stewart@nottingham.ac.uk
}

\begin{abstract}
The emergence of Technology Based Learning has generated a number of pedagogic problems related to learner diversity.. In this paper we present an interim snapshot of a prototype XSLT / XML hypermedia learning environment able to respond adaptively to individual learner profiles using conditional transclusion.

KEYWORDS: Learning environment, adaptive

hypermedia, transclusion, XML, XSLT.

\section{INTRODUCTION}

Technology Based Learning (TBL) - usually in the form of interactive hypermedia - is often represented in higher education as a panacea, a cost efficient means of maintaining teaching quality in the face of declining per capita resources. The rise of the World Wide Web (WWW) has added the dimension of geographical distance to this, allowing for the exciting possibility of globally distributed education [1,2]. However, there remain a number of problems that make the implementation of effective TBL (especially on the WWW) a difficult task. Some of these problems are pragmatic, and others are pedagogic.
\end{abstract}

Although independent learning technologies are extremely good at delivering both information resources and declarative exposition, such forms of delivery constitute only one component of the independent learning process. Laurillard [3] has suggested a "conversational" model of interaction between students and teachers. At the heart of this model is an iterative process of dialogue in which both student and teacher describe their conceptions of the focal issue or topic, and the teacher responds to the student's input "adaptively" in accordance with perceived need. Although this adaptive model can, in principle, be implemented in software, in practice such sophistication is rare. One of the principal pedagogic weaknesses of existing TBL environments is 'static content' - i.e. the system subjects all students to much the same pedagogical experience, regardless of their personal abilities and learning requirements.

In this short paper we will outline one of the key technical aspects in a prototype XSLT (eXtensible Stylesheet Language Transformations) implementation of a framework based upon XML (eXtensible Markup Language). This prototype is called WHURLE (Webbased Hierarchical Universal Reactive Learning Environment) [4] which combines the key requirements specified above in a single, Integrated Learning Environment (ILE). Such an environment models the teacher-learner dialogue, is adaptive to learner needs [5], and processes content structurally predisposed to massproduction, reusability and global dissemination.

\section{DESIGNING FOR ADAPTABILITY - A TIERED, MODULAR APPROACH}

The design for any learning environment is informed by the architect's view of the learning process. As stated above, we see the learning process as a dialogue between student and teacher, where knowledge is passed as discrete parcels or 'chunks' of information, adapted to the needs of the student, during a lesson. To this end we have modeled the process by abstracting information into XML-encoded chunks, the sum of which we have called a 'melange', which are then ordered and organized by a lesson plan, this plan is then provided as a resource to the student, dynamically adapting to their individual requirements, by interacting with their profile to deliver a virtual document. Internal and external linking is provided by a 'linkbase', a construct which interacts with the system to allow linking and content to remain separate.

CONDITIONAL TRANSCLUSION - AN APPROACH One of the original components of Ted Nelson's vision of hypertext was transclusion, where the browser assembled a 'view', comprised of parts of other documents [6,7]. This has rarely been publicly implemented in anything approaching its entirety, although a simplified form may be found in the HTML 'IMG' tag, which allows the inclusion of one type of external resource, namely images, 
to be referenced and included within the document. A recent paper by Pam [8] described ways to implement transclusion, using HTML, but they are complex and mostly impractical.

A simplified model of transclusion, the building of a document via the inclusion of other, smaller pieces, seems an appropriate method to assemble our information fragments. The most tempting way to implement this in our system is to use external entities - these are part of the core XML specification, allowing for the referencing of external resources (usually fragments of XML). The new XInclude specification [9] is also suitable. Both allow for the construction of documents built from the chunks already discussed. The authors would be happy to discuss the technical difficulties of this, and other approaches, with interested parties.

Adaptive hypertext based upon user profiles is a well established discipline [10-12] but the vast majority of it relies on the generation of adaptive links. WHURLE takes a different approach, using conditional transclusion, which is based both upon the user profile and the lesson plan. The profile stores information about the skill set and levels within that set, gathered both actively (e.g. Q\&A) and passively (e.g. page dwell times). The longer the learner uses the system, the more tailored the material becomes. The lesson plan contains two types of material: that which is core to the plan, and that which is supplementary information. If the melange contains it, additional information that is contextually relevant may also be available.

The infrastructure presents the core material in a style (visual and intellectual) determined from the profile. If the student demonstrates particular needs, e.g. by constantly scoring low in maths, the relevant supplementary material becomes available. An adept student, on the other hand, will be progressed rapidly through the lesson plan, encountering the high level material primarily. As the documents are virtual, via their transclusive nature, there is no need for many versions of the same lesson, as each student will encounter the material in a manner best suited to their needs.

\section{CONCLUSIONS}

We have proposed a method to use core XML technologies to implement a transclusive mechanism. This allows the delivery of material suited to each learner, and is envisaged to be a key step in making TBL more efficient and valuable to both the learner and the teacher.

\section{NOTE}

When available, the latest version of the system can be accessed on the development server: http://www.act.nottingham.ac.uk:8080/cocoon/start.html

\section{ACKNOWLEDGMENTS}

The authors wish to thank Peter Murray-Rust and Helen Ashman, and Ban Seng Choo for many useful discussions, and colleagues at the Virtual School of Biodiversity (VSB) and IBiS for their support and encouragement. Craig Stewart is a VSB research associate funded by the Hong Kong University Grants Committee.

\section{REFERENCES}

1. Davies, P.M.C. The Virtual School of Biodiversity: a model for quality assured distributed learning. IN: eEducation: Challenges and Opportunities, Proceedings of the Fifth Hong Kong Web Symposium (eds. F Castro, R Lai and Sr M Wong), Social Sciences Research Centre, The University of Hong Kong. (1999) Available via:

http://vsb.nott.ac.uk/vsb/papers/hk_conf99.html

2. Anderson, M. \& Jackson, D. Computer systems for distributed and distance learning. Journal of Computer Assisted Learning, 16 (2000), 213-238.

3. Laurillard, D. Rethinking University Teaching: A framework for the effective use of educational technology. (1993) Routledge.

4. Brailsford, TJ ; Moore, A ; Stewart, CD ; Zakaria, MR ; Choo, BS ; Davies, PMC. Towards a framework for effective web-based distributed learning. (Proceedings of the $10^{\text {th }}$ International World Wide Web Conference, In Press)

5. Danielson, R.L. Work in progress: Learning styles, media preferences, and adaptive education. Proceedings of the workshop "Adaptive systems and user modelling on the world wide web. (1997)

6. Nelson, T.H. Literary Machines. (1980-1993) Mindful Press, Sauslito, CA.

7. Nelson, T.H. The Heart of Connection: hypermedia unified by transclusion. Communications of the ACM, 38, 8 (1995), 13-33.

8. Pam, A. Methods for implementing transclusion of text into HTML pages. (1996) Available via: http://xanadu.com.au/xanadu/transclude.html

9. W3C Working Draft (2000). XML Inclusions (XInclude) Version 1.0..

10. Brusilovsky, P. Adaptive Educational Systems on the World Wide Web: A review of available technologies. Proceedings of the Workshop "WWW-Based Tutoring" at the 4th International Conference on Intelligent Tutoring Systems (ITS'98). (1998).

11. Brusilovsky, P.; Eklund, J.; \& Schwarz, E. Web-based education for all: A tool for developing adaptive courseware. Computer Networks and ISDN Systems (Proceedings of Seventh International World Wide Web Conference) 30, 1-7 (1998), 291-300.

12. Brusilovsky, P.; Schwarz, E.; \& Weber, G. A Tool for Developing Adaptive Electronic Textbooks on WWW. Proceedings of WebNet'96 - World Conference of the Web Society, 1996. San Francisco, CA, AACE. - pp. 64-69 